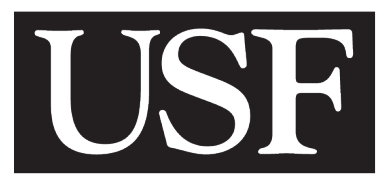

Muma Case Review

A publication of the Muma College of Business | University of South Florida

\begin{tabular}{lll}
\hline Volume 6 & Number 18 & 20 JULY 2021 \\
\hline
\end{tabular}

ALTON DOE, JOHN FIELDS, NEERAJ GULATI, ERIK RAUCH

\title{
IS IT TIME TO RETIRE? ${ }^{1}$
}

"Technology, for many businesses today, has become life or death. ConServ Building Services had come to a technology fork in the road and needed to choose a path." -Brad McIntire

Brad McIntire, President of Conserv Building Services, sat in his office, wondering if it was time to retire. Once again, Technology, his nemesis, had derailed his organization and brought it to a standstill. Brad was thinking, "I think these I.T. guys are literally going to be the death of me."

The issue faced by Brad and Conserv Building Services started with a bug in the mobile device management (MDM) software. The MDM software had a feature to auto-approve applications and pushed the approved applications to the tablets used by technicians in the field to provide real-time customer service. For some unknown reason, the MDM software unexpectedly unapproved and uninstalled all applications on the tablets and would not let them be reinstalled on over 200 tablets. This brought the company to a standstill as this paperless software system was the only means to provide data to its customers in real-time. Conserv had built their competitive advantage in bringing this data to customers in real-time. This first instance of the glitch took down the organization for five days until it was resolved, costing the organization around one million dollars in lost revenue. The second instance of the bug resurfaced less than a month later, causing an outage for a little over one day and the loss of income of around two hundred and fifty thousand dollars. These outages did not take into account the cost of resources from the I.T. department and management time dealing with the crisis. Air conditioning services are the type of thing that cannot wait, and customers demanded prompt service.

Some positive signs were on the horizon. The MDM software company acknowledged that they did have a bug and would provide a fix very shortly. The I.T. department was encouraged that a patch was right around the corner. Brad was less confident that just because the software company agreed that there was a known issue that a resolution would be quick to follow. Brad knew that leaving an electronic system was impossible in the current environment. Customers wanted more data quicker and faster. But could the organization remove some of the reliance on technology and software? Would the I.T. department come up with a plan that created a stable environment? Should the organization spend even more money on a new hardware platform? How much revenue would be lost with the next glitch?

${ }^{1}$ Copyright (C) 2021, Alton Doe, John Fields, Neeraj Gulati, Erick Rauch. This case was prepared for the purpose of class discussion, and not to illustrate the effective or ineffective handling of an administrative situation. Names and some information have been disguised. This case is published under a Creative Commons BY-NC license.

Permission is granted to copy and distribute this case for non-commercial purposes, in both printed and electronic formats. 


\section{Construction Industry}

With over 20 years of experience within the construction industry, Brad had witnessed significant change throughout the "secondary" sector of the economy. The total global construction output in 1998 was estimated at $\$ 3$ trillion. The majority (70\%) of this output was concentrated in higher-income areas like Western Europe, North America, Japan, and Australasia (INTERNATIONAL LABOUR ORGANIZATION, 2001). The industry had continued to play a major role in the global economy and accounted for $\$ 10$ trillion in goods and services annually. The U.S. trailed only Asia Pacific and Europe and accounted for $\$ 2$ trillion in the 2019 market space. This $\$ 2$ trillion output in the U.S. was spread amongst the various sectors: residential, commercial, heavy civil, industrial, and environmental construction.

As it pertained to the U.S., there were more than 680,000 employers and over 7 million employees operated within the industry, that contributed to $\$ 2$ trillion in goods and services ("The Associated General Contractors (AGC) Of America Construction Data", 2020). A 2019 data measure showed the construction industry contributed $4.1 \%$ to the U.S. gross domestic product, with continued growth. Conserv worked within the Heating, Ventilation, and Air Conditioning (HVAC) space in the industry.

In 2019 alone, data showed HVAC accounted for $\$ 96$ billion in annual revenue, with $2.9 \%$ yearly growth between 2014-2019, 118,200 businesses listed, and over 530,000 people employed ("Value Added by The Construction Industry", 2020). The numbers reflected the consistent growth within the industry with plenty of competitors. Competing organizations were set apart by their ability to leverage competitive advantages. Technology had become the catalyst for many of these competitive advantages.

\section{Technology in Construction}

As one broke down the technological advancements through the construction industry, dynamic innovations ranged from tools to machinery and software. This tech transition had made construction activities faster, safer, and smarter, enriching project scale abilities. Although some organizations had found these advancements disruptive, most of the competitive companies digitally transformed everything from filing systems, data collections applications to communication tools between servicing departments and mobile service technicians.

The Technology significantly enhanced the quality of service and had made real-time customer service the new expectation. The inability to fulfill real-time expectations placed customers in the hands of a competitor. The HVAC sector suffered from this dynamic.

\section{HVAC Competitors}

With increased temperatures and unpredictable climatic conditions, HVAC equipment was a beneficial investment in all facets of residential, commercial, and industrial construction. Customers want to receive these goods and services from competitors that offer a wide range of services. The major HVAC competitors in the Southeastern region of the U.S. include companies like:

- Source Refrigeration

- Trane

- Johnson Controls

- Carrier Construction

- CMS Construction Management Solutions 


\section{Conserv Building Services}

Conserv Building Services was a significant HVAC player in the Southeastern Region of the U.S. In the Southeastern US, Conserv stood as one of the largest HVAC service providers that leveraged a staff of over 200 professionals and field personnel that self-performed these services. Their geographical presence and reputation for quality service secured major customers such as:

- Bed, Bath \& Beyond

- Target

- Circle K

- 7- Eleven

- CVS

Exhibit 1 shows the geographical area that they serve.

\section{Company Overview}

ConServ Building Services, LLC was established in 1991 and had its Corporate headquarters in Largo, FL. It offered construction services, HVAC (heating, ventilation, air conditioning) services, preventative maintenance, repair, and 24-hour emergency service. It originally expanded with organic growth providing these services statewide in Florida and then later further expanded with acquisition growth throughout the Southeastern U.S.

ConServ had offices and provided services in Alabama, Florida, Georgia, Mississippi, North Carolina, South Carolina, Tennessee, Virginia, and Texas. One of its attractive features is that it had the flexibility of a small firm with the resources of a large corporation. ConServ had experienced consistent growth since its inception and continued to expand further.

Brad identified that the core competencies/competitive advantages of ConServ Building Services, LLC were the following four areas:

\section{Trained Technicians $24 / 7 / 365$}

ConServ employed over 200 licensed technicians in the Southeast United States who were dispatched via a web portal, email, and phone. Conserv's licensed HVAC technicians were trained to service the latest commercial and industrial air conditioning, heating, and refrigeration equipment. They also had commercial plumbers and electricians on staff. Conserv's service professionals underwent an extensive training program. They had even offered apprenticeships through local Associated Builders and Contractors various chapters, monthly in-house training sessions, manufacturer certifications, state certifications, and much more. Their technicians were knowledgeable and were ready to help customers find solutions for their facilities.

\section{Personalized Service Centered Around State-Of-The-Art Technology}

ConServ offered round-the-clock remote monitoring and control of heating, ventilating, and air conditioning; customer access to system data and reporting via a web portal in real-time. This helped the customer control costs and improve equipment efficiency as the Customer Portal management system automatically kept track of refrigerant usage for every piece of equipment they had serviced. Customers were able to monitor which units or locations used the most refrigerant. The system provided information to help customers make informed decisions about their HVAC equipment. The refrigerant cost was expensive and had significant environmental concerns to the end customer from governmental agencies. 
The system allowed customers to see how much they had spent at each location by custom date ranges, as shown in Exhibit 2. The portal also permitted for the breakdown of the type of repairs, as shown in Exhibit 3. This information was available in real-time.

In addition, the paperless digital form system allowed the electronic transfer of information to and from the field quickly. Service technicians were equipped with portable tablets that had given them instant access to important information about the service history of each piece of equipment. The data also included client locations and any special instructions that may be on file. Fast access to accurate information was the key to get the job done. Brad always found that the techs on-site could instantly check to see what had been done previously, had made for more effective service experiences for the customer.

\section{HVAC and Beyond}

ConServ's turn-key offerings included HVAC installation, service \& maintenance; controls, refrigeration, electrical, and plumbing; thermographic scanning, test \& balance, equipment commissioning, retrocommissioning, and general maintenance. The company also offered online training modules through ConServ University, which was available online to the technician group.

\section{End-Markets Served}

ConServ specialized in service work for commercial, entertainment, institutional, healthcare, laboratory, and data center end-markets. It was affiliated with ISNET WORLD (see Exhibit 4) and was a proud member in good standing. This membership showed to customers that they were also safety-minded. Conserv was as concerned about safety on client sites as were their customers. Conserv had tremendous success over the last couple of decades. There was no doubt that it had built a solid reputation and had become a leader in the industry.

No matter the client, data was still needed, and the organization provided it to the customer. Technology is what drove the customer experience and helped Conserv get this valuable information to the client. Part of the technological solution included the mobile device management software system.

\section{Mobile Device Management (MDM)}

In just a few short years, the way employees used the mobile device had shifted dramatically. However, with this trend came new considerations for security, connectivity, privacy, and management. This gave rise to mobile device management (MDM) software. It was software used by the I.T. department to monitor, manage, and secure employees' laptops, smartphones, tablets, and other devices used in the workplace. With security and data breaches being costlier every year, MDM tools became essential to the modern workplace. With the help of this software, access to any application was easily denied or controlled, as illustrated in Exhibit 5 (Raza, 2019).

Conserv used the Cisco Meraki (MDM) product to provide unified management of mobile devices, Macs, P.C.s, and the entire network from a centralized dashboard. The Meraki Dashboard integrated directly with Google Play and both the iOS and macOS App Stores, which allowed users to quickly and easily configure and deploy apps to their mobile devices. Additionally, enterprise apps were supported on both iOS and Android platforms.

There was a need for Conserv Techs to open and view all the work order information at the client-site quickly, like accessing work history, notes, blueprints, or schematics, which greatly expedited complicated diagnostics and repair time. Conserv used TechAnywhere as the comprehensive mobile field service software to help Techs streamline communication between the field and the back office for the 
work orders. This software was accessed by the techs using tablets. All new work order information entered by techs was automatically stored in the software and shared instantly with the back office and customers.

\section{Software Failure}

MDM, or Mobile Device Management, a software that permitted I.T. administrators to not only secure, control but also enforce policies on smartphone, tablets \&, other electronic equipment's. If the MDM software moved the application to unapproved status, then the application on the tablet would be uninstalled. The approval process, as illustrated in Exhibit 6, broke between the MDM and TechAnywhere software; this was due to a software bug in MDM. This bug caused the paperless software application to be removed from over 200 tablets automatically. Conserv had built their competitive advantage by bringing this data to customers in real-time. This bug brought the company to a standstill as this paperless software system was the only means to provide data to its customers in real-time.

The Software malfunction occurred at Conserv with their MDM system was due to the auto-approval status that kept switching to unapproved from approved, as shown in Exhibit 7. This issue resulted in all the applications being uninstalled on the tablets. The I.T. department was unable to get the application reinstalled when this issue arose. The only solution involved the technicians downloading a file manually to get the paperless application to work. To overcome the glitch was time-consuming and involved the management hand holding the techs as they reinstalled the application manually. Brad knew that every major competitor had their own MDM Software system to manage their hardware, but did everyone else have the same challenge?

\section{Preventing Software Failure}

Software Testing is conducted to increase the quality of the software products as a standard practice on test environment prevented issues from occurring in a live setting. The MDM software was never tested before being rolled out. The cost to detect and fix defects in software increased exponentially with time in the software development workflow. When bugs were fixed in the field, it was incredibly costly and risky — often by order of magnitude or two. As illustrated in Exhibit 8 (Sanket, 2019).

Most defects ended up costing more than it would have cost to prevent them. Defects were expensive when they occurred, both the direct costs of the flaws and the indirect costs because of damaged relationships, lost business, and lost development time.

Software malfunction or bugs can be reduced by thorough testing that could have prevented its occurrence even better if its automated. Automation testing - It could have saved hours of development time and many operational headaches. It was not merely clicking around your store randomly to see if things were working. Instead, it was the actual code that tested other parts of the code for issues. This solution was the use of code that tested code which is repeatable and regressive in nature.

\section{Business Continuity and Disaster Recovery (BCDR)}

The Technology is only as good as your Business-Continuity disaster-recovery plan (BCDR), as shown in Exhibit 9. BCDR was often overlooked in the business. It was crucial to account for recovery scenarios conceptually. The role of BCDR was to minimize the effects of outages and disruptions on business 
operations. Had there been a plan to handle Disaster, software failure, bugs or natural calamities the impact could have been minimized.

BCDR practices enabled an organization to get back on its feet after problems occurred. It reduced the risk of data loss and reputational harm, and it improved operations while it decreased the chance of emergencies. The goal of BCDR was to limit risk and get an organization running as close to normal as possible after an unexpected interruption.

A business that's unable to deliver services struggled to attract workers and customers. Lack of BCDR at Conserv caused complete failure rather it could have automatically launched the BCDR, and the system would have been back up and running much quicker, which would have minimized the risk of delays and guaranteed reliability of critical systems as single day downtime costed about $250 \mathrm{~K}$.

\section{Technology Impact at Conserv}

Conserv had always struggled to implement the latest Technology and data gathering tools. Their customers pushed to have more data at a quicker pace. The customers that used Conserv's services were generally larger and more sophisticated organizations that had a multi-state geographical presence. The customers wanted and needed the data to help them in their decisions on their maintenance spend. If the climate was unpleasant at a location, it had a tremendous impact on revenue spent. The typical customer had real-time data on which units were down, and for how long the units had been down. They also knew the impact this had on sales.

This was where Conserv came in with real-time data. The customer would receive the problem, cause, and remedy of the service call. They would know when the tech was on-site and when the tech was finished with the call. They would get all of this data in real-time, which helped the customer with their decision. They could log in via a customer portal, as shown in Exhibit 10 to get to their data.

This exchange of data at one time was a competitive advantage; it became more of a requirement for larger customers demanding this of their vendors. Customers judged their vendors on the quality and timeliness of the data. Brad recalled a visit to a customer during their contract renewal. By showing the customer their data and pointing out that a simple repair comprised $25 \%$ of their service calls, and that a simple maintenance program performed at a fraction of the cost reduced the number of service calls. That exchange of information resulted in a renewed contract. The customer paid a premium on the renewal due to this presentation.

The actual paperless work order system was designed to be able to work offline and send data back to the server once service was re-established. The remote offices kept additional hardware in stock whenever an issue arose. The organization had gotten used to free-flowing data and the ability to respond back to a customer with details of the repair. The firm sent invoices to its customer in a matter of hours instead of days. Technology had been the key to keeping overhead down and provided a lower-cost solution for customers. Customers got information timely, and they got it at reduced cost. Brad lamented on the disaster recovery plan that was in place every time a failure happened with this MDM platform. It was not a pleasant thought, as the recovery plan was to revert to a paperwork order system that was slow and arcane.

The MDM software was not new for Conserv. Conserv attempted three different MDM products prior to this one. The lack of testing and planning the prior three versions was the primary reason that they failed. The fourth product had been up and running for about a year before the problems began. The fourth version had shown some promising signs. It helped keep track of the tablets due to loss and theft. The MDM had also increased productivity by keeping unwanted applications from being installed. It also 
helped the accounting department control the spending on data from cellular providers. The MDM reduced the expense by over $\$ 150,000$ a year. The streaming of movies and video poker were now a thing of the past.

The downtown time from a glitch cost the organization real money. A single day of downtime had costed the organization between $150 \mathrm{k}$ to $250 \mathrm{k}$ of revenue. The indirect costs were also felt, but this was much harder to recognize. The management of overhead expenses had caused the managers to be extremely busy with day-to-day activities. They did not have the time available to maneuver the company via a manual system. Conserv was in the middle of contract negotiations with their largest customer. The outages hurt the renewal of the next three-year contract. The failure to provide good quality and timely service was terrible for talks.

The outages also impacted the technicians and the overall mood of the firm. Technicians did not appreciate their jobs made more difficult due to outages. Initially, when the techs were given tablets, they had resisted switching from a paper ticket. After a short period of time, the techs fought if they were forced to use a paper ticket in lieu of their tablet. Technicians were hard to come by, even more challenging than new revenue streams. The firm had to continually engage with the employees to prevent from losing them to a rival competitor. The techs changed jobs over even a small pay raise or bonus. The trades had seen fewer and fewer employees entering into this line of work. During this crisis, the demand for techs was greater than the supply. The organization could not afford this dysfunctional environment this glitch caused. Techs left the company over this issue alone. The organization as a whole became reliant on Technology, and the business had to come up with a solution that made sense to fix this mess. The time to create a resolution had become critical.

The company had chosen at the time to use an android version of the hardware. The Apple version was much more expensive. Techs were notoriously bad at taking care of the tablets, and Android tablets were cheaper to replace versus Apple products. The I.T. department had determined that Apple tablets were more reliable and had fewer issues than Androids. The other operating companies had used Apple without issue and had even used the same MDM product. Management was criticized at the time for not spending money on a better hardware system. At the time, it was estimated that the cost to switch to Apple products would have been around a 50k increase on an annual basis.

\section{The Decision}

Brad knew the decisions were not simple, and the company had only come with four possible solutions. The first option that came to mind was reasonably straightforward but required the longest lead time and likely would cost the most. Conserv would reach out to the paperless software company and would have them create an interactive webpage. This webpage would allow the technician to enter their data and call info directly into a secure portal should the application be removed from the tablet. This feature did not exist and would have to be done over some time and would be customized to interface with Conserv's backend servers. It would require a data connection in order to work, which was not required currently with the application they used. This would be a better alternative reverting back to paper when the next outage occurred. Data service at the time was not always consistent and not always available to be used. The company became more reliant on data service and web servers to work during an outage.

The second option was to replace all the hardware in the organization. This would cost more than just the initial spending on the actual hardware. All the tablets would have to be configured and timed to switch out all 200 tablets at one time. The software company's interface required either 100\% Apple or 100\% Android usage, so the switch would have to happen simultaneously. The cost to replace broken or 
outdated tablets would be much more expensive over time. The solution allowed the organization to use the current MDM software without worrying about the glitch.

The third option would be to provide a monthly allowance to each tech for them to purchase their own tablet and service. This would remove the need to use an MDM altogether. The application would be in a stable environment without an MDM product. Should the tablet be lost or stolen, it would now fall to the tech who owned the tablet. The only real issue was the ability to download an application that may not be work-related and may reduce efficiency in the field. The tablets may end up with potential viruses, but the impact on the overall security of the network would be minimal as the rest of the network has appropriate security and firewalls in place. The tech, though, would be responsible for the data usage, which may encourage them only to use it as it was necessary. The other concern related to pushing this responsibility onto the tech and the impact to them personally.

The last and fourth option, which really was the typical do-nothing option, existed. The company could wait until the MDM software firm provided a patch to remedy the glitch. The time frame on the patch was uncertain, and the outages were incredibly damaging to Conserv. The question was, how long would it be until the next outage?

\section{References}

Conserv Building Services, LLC (2020). Retrieved from: https://conservonline.com.

INTERNATIONAL LABOUR ORGANIZATION. (2001). The construction industry in the twenty-first century: Its image, employment prospects and skill requirements. https://www.ilo.org/public/english/standards/relm/gb/docs/gb283/pdf/tmcitr.pdf

Raza, M. (2019). Mobile Device Management. Retrieved August 2020, from BMC Blogs: https://www.bmc.com/blogs/mdm-mobile-device-management/

Sanket. (2019). Exponential cost of fixing bugs. Retrieved August 2020, from https://deepsource.io/blog/exponential-cost-of-fixing-bugs/ 


\section{Biographies}
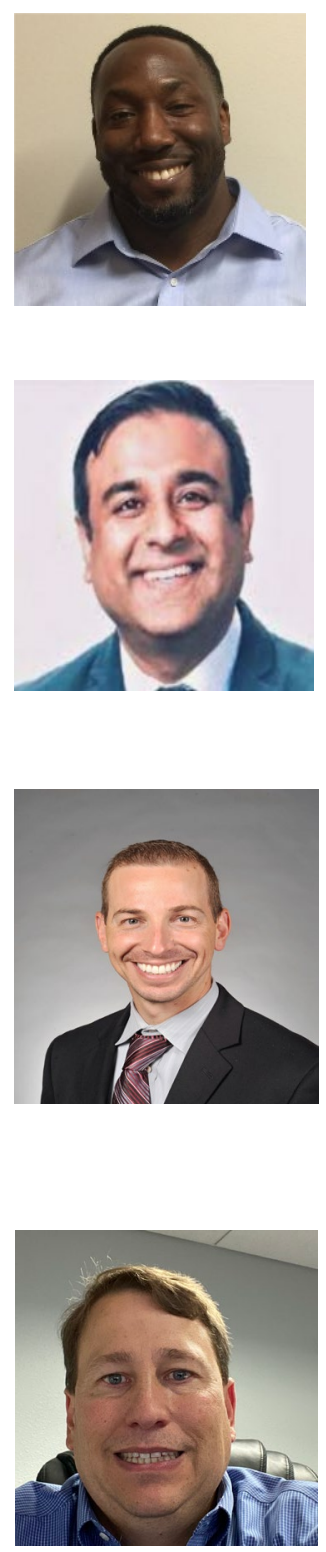

Alton Doe is a 20-year veteran of the U.S. Air Force. He earned a bachelor's degree in business management from the University of Phoenix and an Executive M.B.A. from the University of South Florida's Muma College of Business. Diverse experience in health care, aviation, emergency management, regulatory compliance, and foreign affairs. He specializes in building internal/external partnerships, national/international relations, and developing solutions while driving high operational effectiveness.

Neeraj Gulati, Vice President, JPMorgan Chase, Technical leader with more than 15 years of hands-on experience in managing the development of software applications and computer systems for various clients as per time and budgetary constraints. Expertise in design, data structures and algorithms, and strong analytical and debugging skills with customer-facing products experience. Strong experience in introducing Agile and Kanban concepts within the development team. He earned a bachelor's degree in Technology, Information Technology and is currently enrolled in USF's EMBA program.

Erik Rauch is the Senior Director for Advanced Practice Providers with Envision Physician Services. In that administrative role, Rauch plays an integral part of the leadership team for all anesthesia services. He also clinically performs anesthesia services for obstetric, trauma, general, vascular, plastics, and orthopedic cases. Rauch earned a Doctor of Nursing Practice degree from USF (2011) and a Certified Registered Nurse Anesthetists degree from Florida Gulf Coast University (2006), along with a graduate certificate in advanced pain management from Hamline University (2014). He is expected to graduate from USF's EMBA program in May 2021.

John Fields is the President of BCH Mechanical. In this administrative role he is responsible for the day to day operations of a Mechanical Contractor located in Florida. He is also responsible for the sister company Conserv Building Services that provides commercial HVAC services in the southeastern US. Fields is a licensed CPA in the State of Florida, and received a degree in Accounting from the University of South Florida. He is currently enrolled in USF's Executive MBA program. 


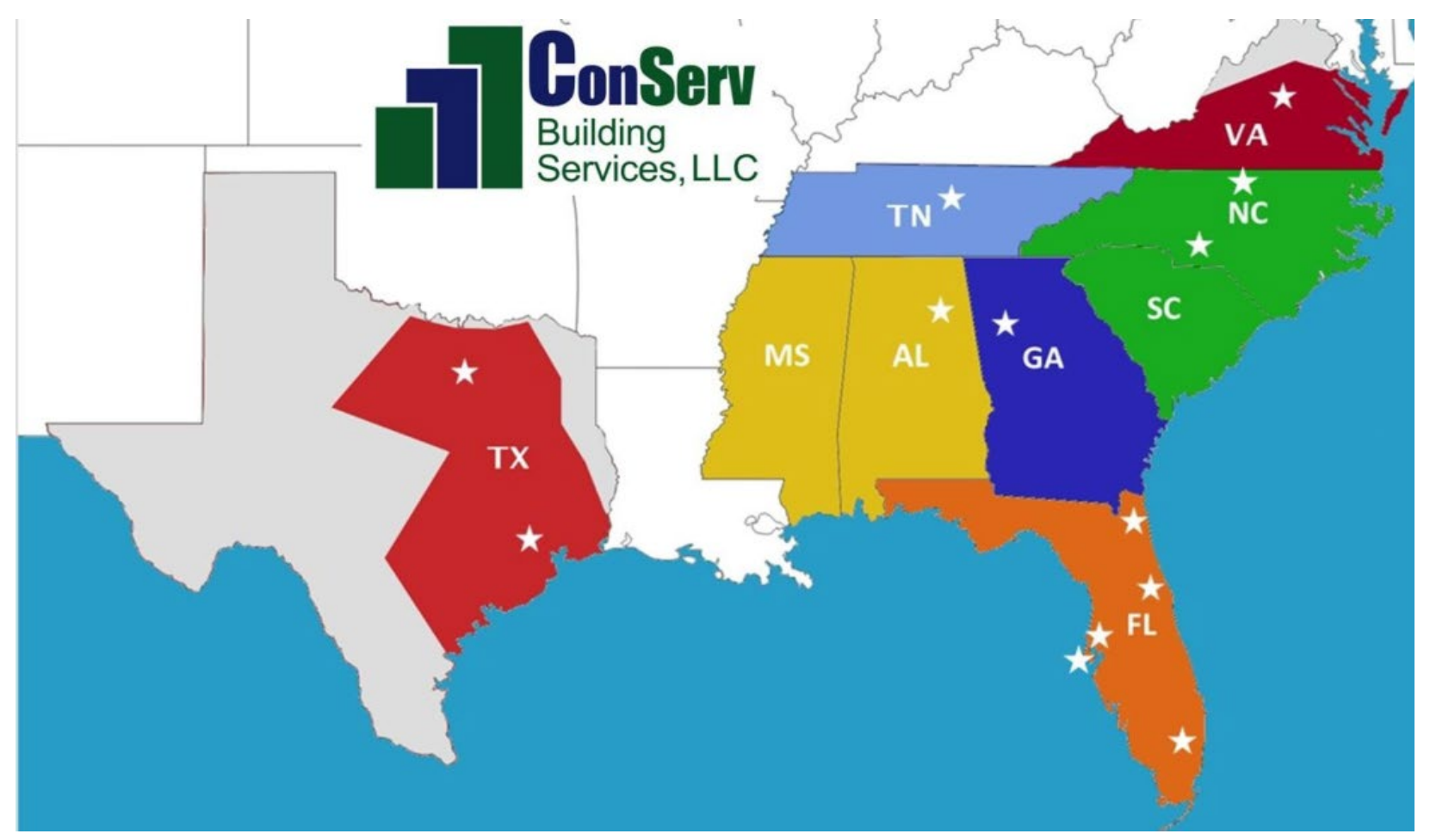


Exhibit 2: Dollar spend by location for a specific customer

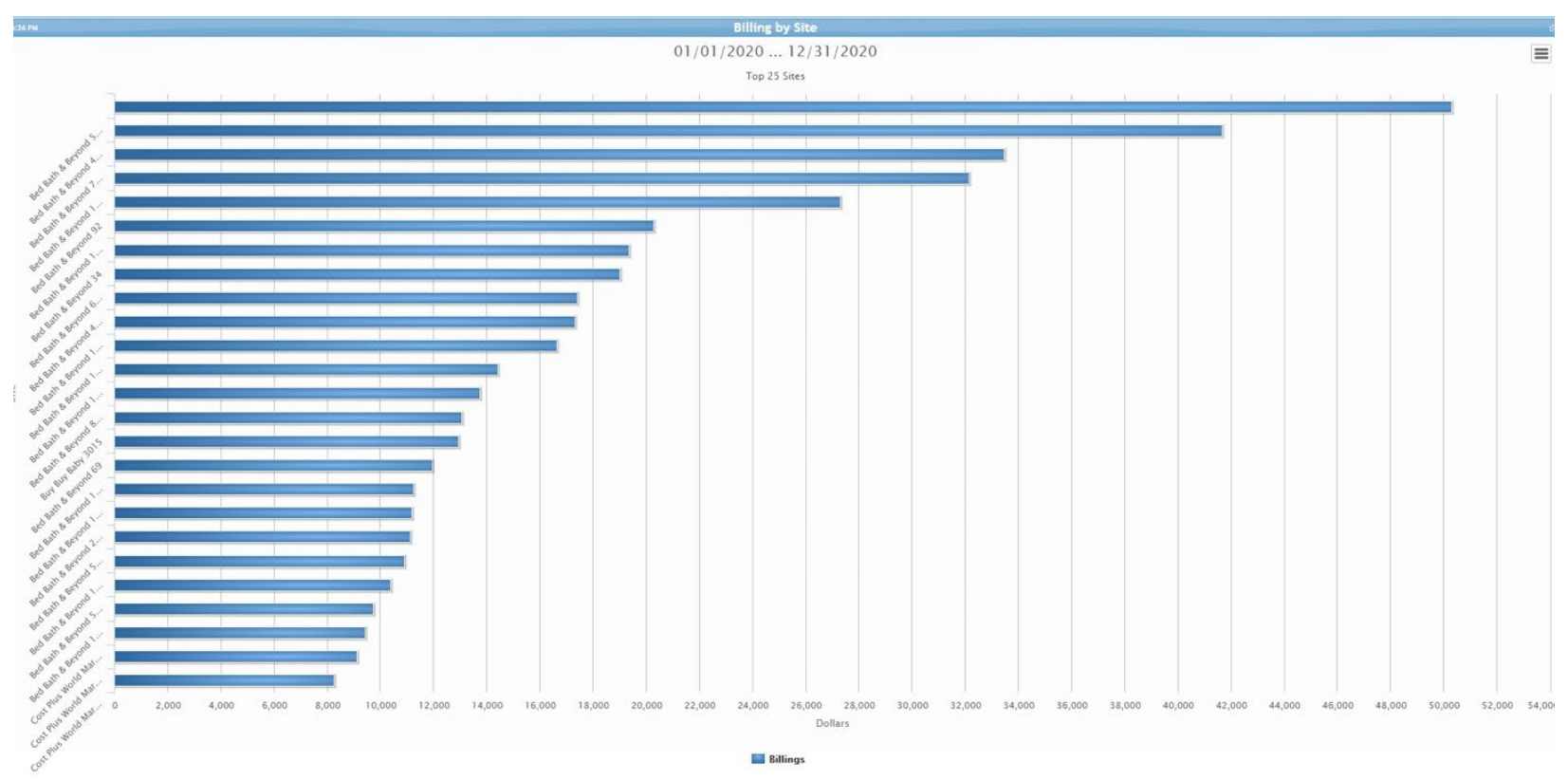




\section{Exhibit 3: Percentage of work orders for a specific customer}

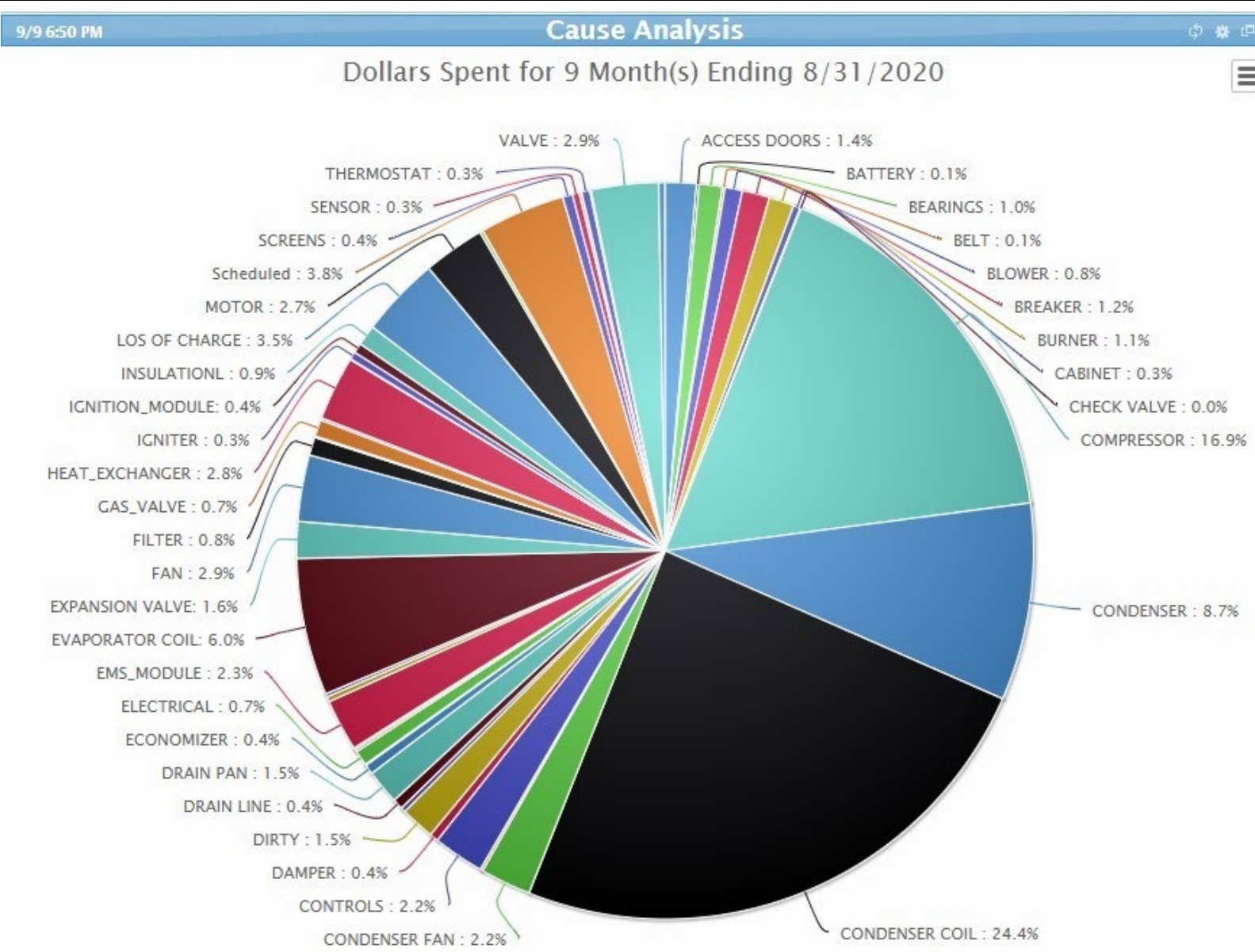




\section{Exhibit 4: Safety Certification}

\section{AFFILIATIONS}

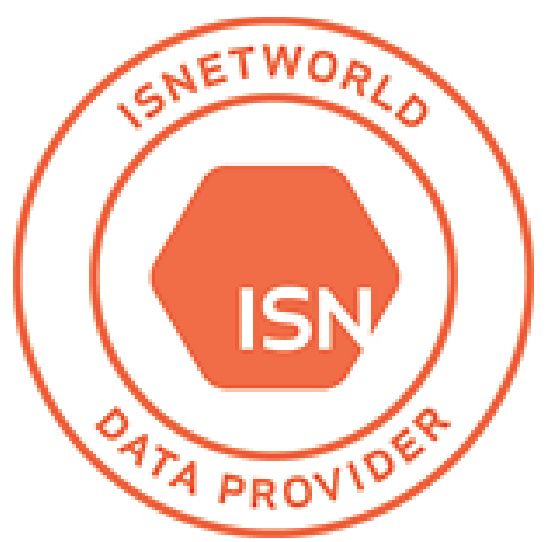




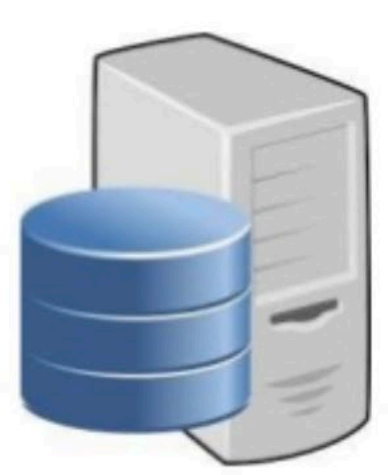

CENTRAL IT MANAGEMENT

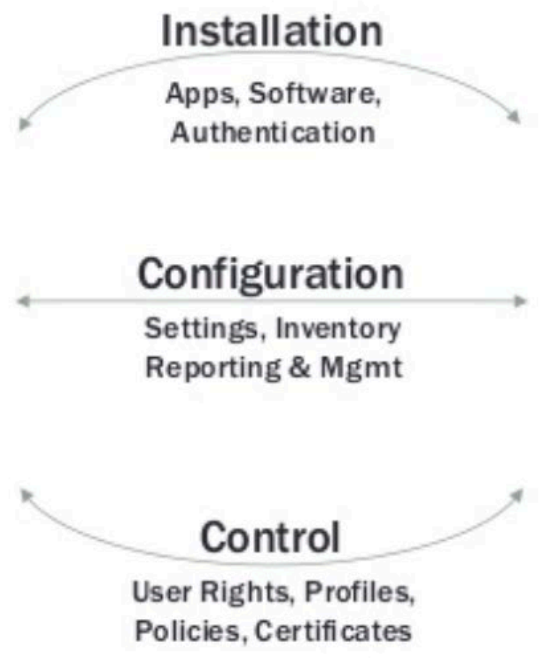

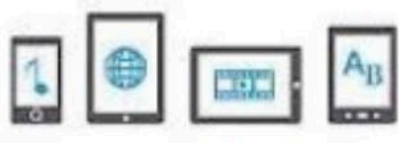

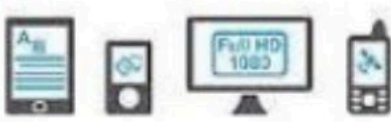

USER

DEVICES 


\section{Exhibit 6: High Level Architecture of Approval process for MDM}

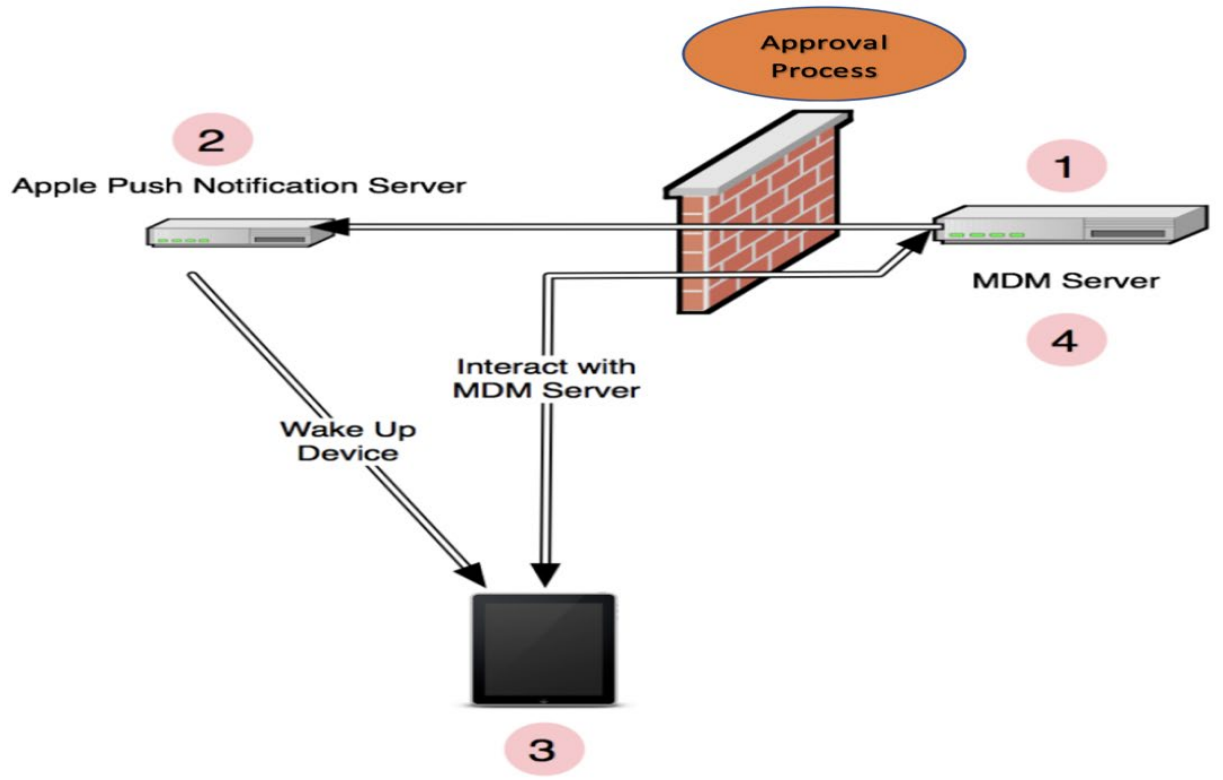




\section{Exhibit 7: MDM Software with approval glitch}

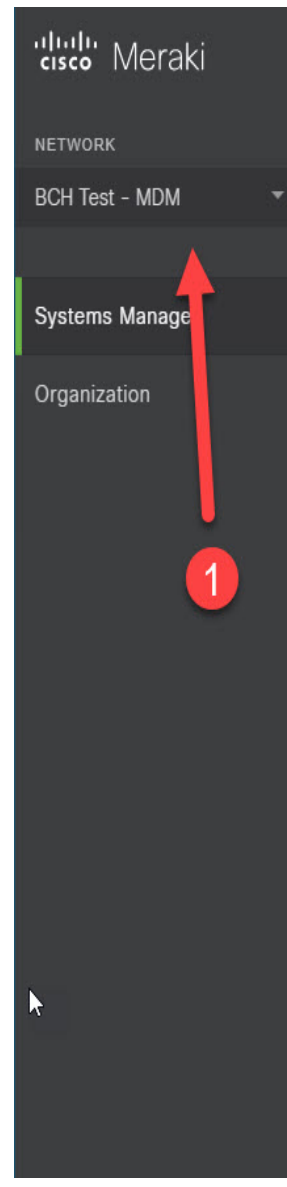

Q Search Dashboard

New in Dashboard: Dashboard API - Version 0.9 Released and 2 other features. Read more.

Apps list / TechAnywhere

TechAnywhere * Android

Data-Basics

Details

Identifier

Price

Source

Type

App source

Refresh details $\boldsymbol{\approx}$ View in Play Store $\square$

\section{Options}

Auto-install / auto-uninstall $\mathbf{0}$

Remove with MDM 6

Visible in SSP 8

Approval status

Approval date

Approval status
Store

com.databasics.techanywhere

Free

Store
च

$\square$

จ

Sep 032020 13:53 EDT

Reapprove Unapprove
Play Store App 


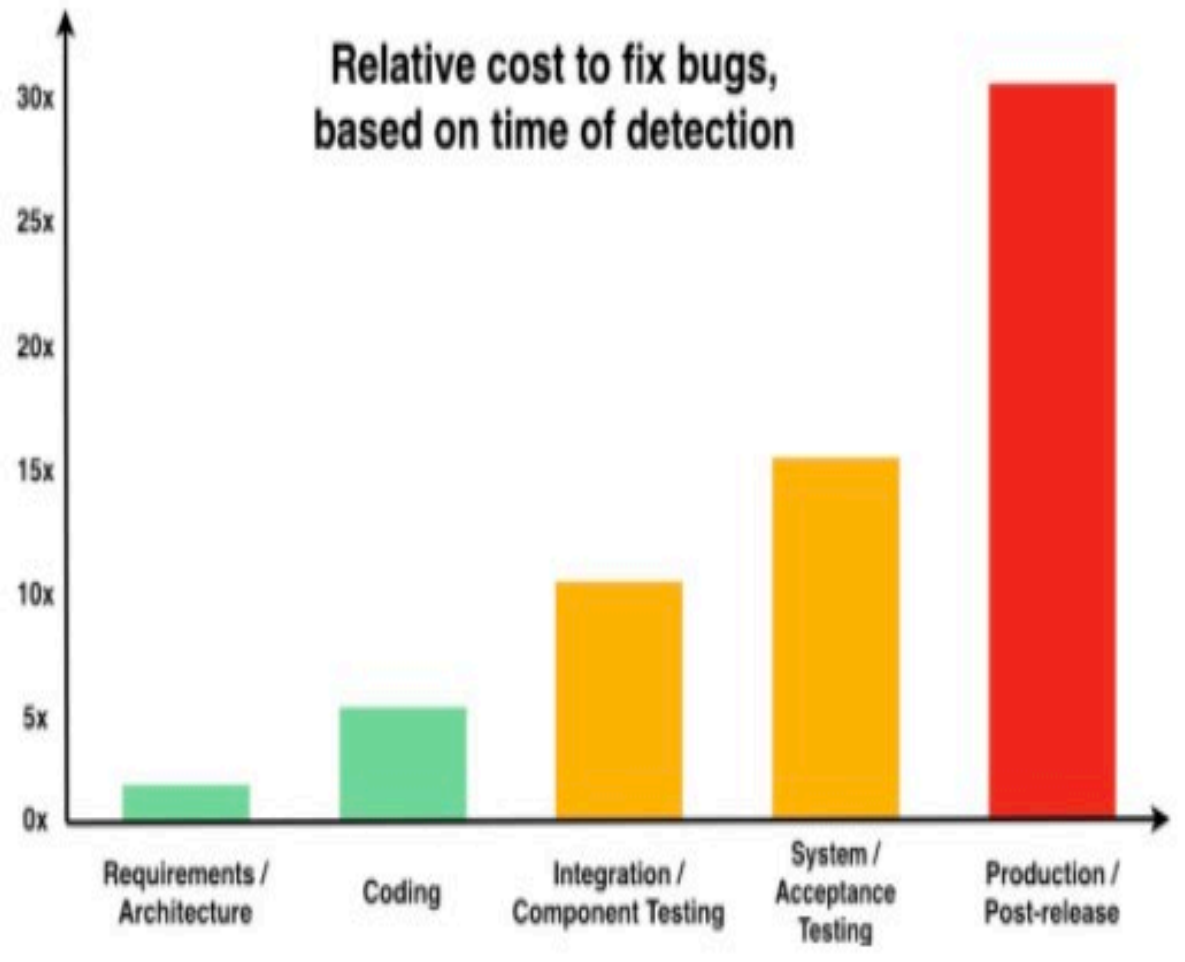




\section{Exhibit 9: Business Continuity and Disaster Recovery Plan}

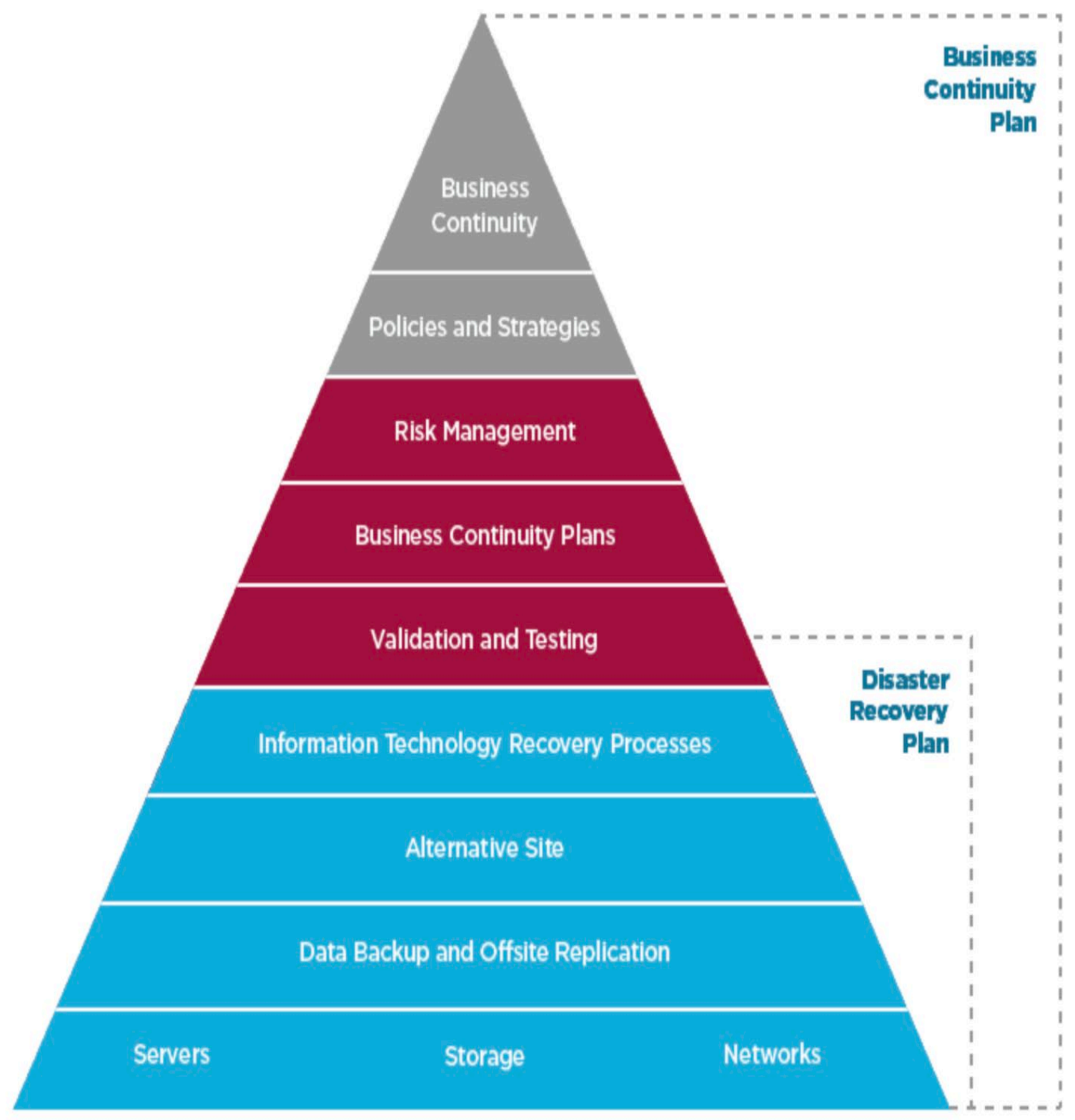


Exhibit 10 : Customer Portal Login

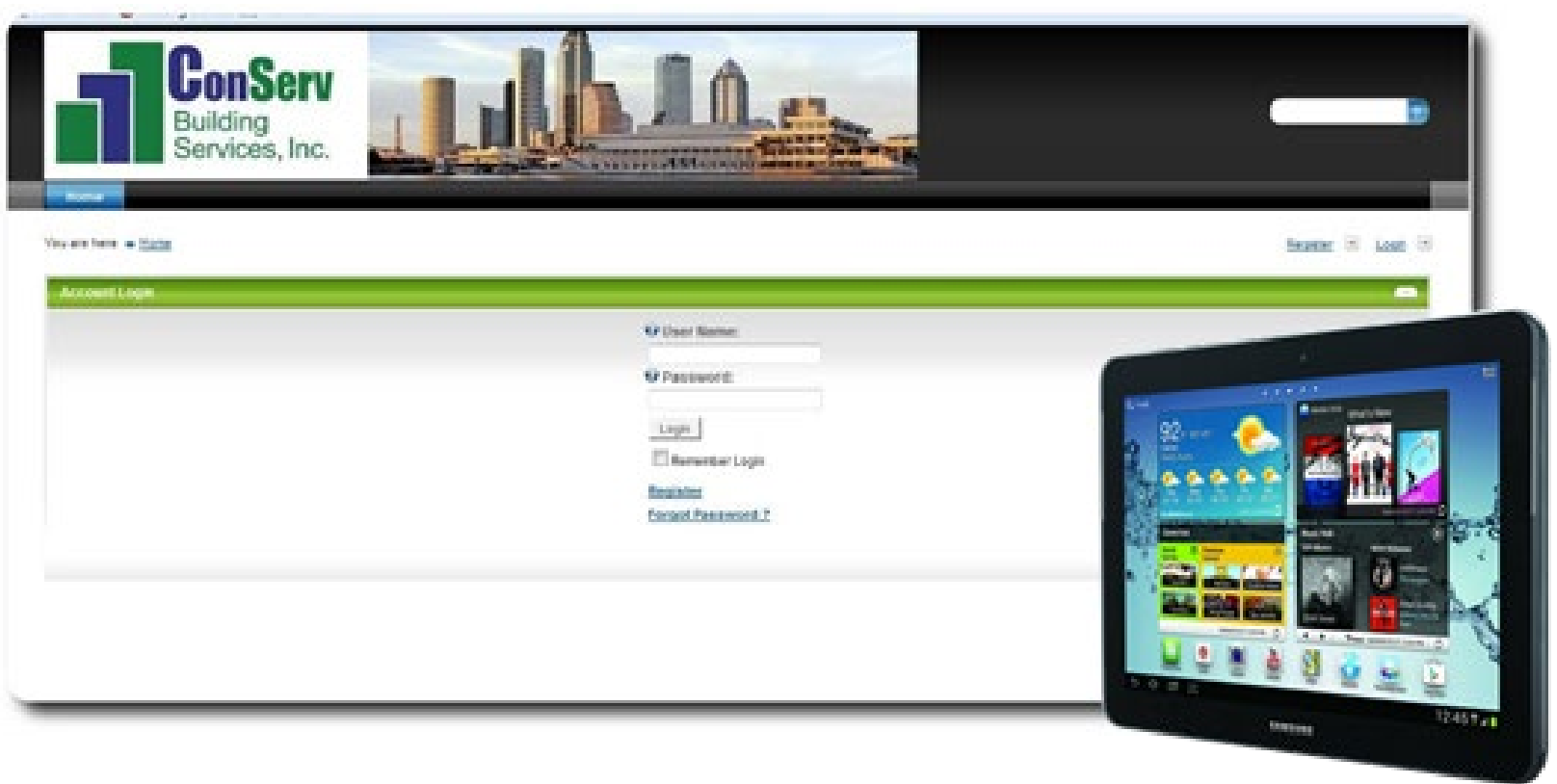

